\title{
Confounding Imaging Findings in Subacute-Chronic Cerebral Infarction
}

Hernández-Díaz ZM*, Barroso-García E, González-García S, González-Quevedo A, ReyesBerazaín A and Arteche-Prior M

Department of Neuroimagenology, Institute of Neurology and Neurosurgery, Cuba

*Corresponding author: Hernández-Díaz ZM, Institute of Neurology and Neurosurgery, Calle 29 y Esquina D La Habana, Cuba

Received: May 10, 2017; Accepted: J une 02, 2017; Published: J une 21, 2017

\begin{abstract}
Imaging findings which appear during the course of subacute and chronic cerebral infarct and which can lead to confusion for diagnosis is presented in a series of six patients. These include: luxury perfusion, fogging effect, hemorrhagic transformation, Wallerian degeneration, diaschisis, laminar cortical necrosis and encephalomalacia with exvacuum dilation.
\end{abstract}

Keywords: Subacute infarct; Chronic infarct; Luxury perfusion; Fogging effect; Hemorrhagic transformation; Wallerian degeneration; Diaschisis; Laminar cortical necrosis; Laminar cortical necrosis encephalomalacia; Exvacuum dilation

\section{Abbreviations}

MCA: Medial Cerebral Artery; ACA: Anterior Cerebral Artery; WD: Wallerian Degeneration; CT: Computerized Tomography; MRI: Magnetic Resonance Imaging; FLAIR: Fluid Attenuated Inversion Recovery; CBF: Cerebral Blood Flow; SPECT: Single-Photon Emission Computed Tomography

\section{Introduction}

After occlusion of a cerebral artery, imaging studies confirm cerebral infarction during hyper acute and acute phases [1-3]. This allows engaging in therapeutic decisions with the aim of reducing damaged tissue and thus the subsequent sequels.

Nevertheless, imaging findings can occur during subacute and chronic phases of cerebral infarction that could disguise or mimic other neurological processes. Although these findings have been described in the literature, in many occasions they are overlooked and can originate confusion when conducting imaging diagnosis. Among these are: luxury perfusion, fogging effect, hemorrhagic transformation, Wallerian degeneration, diaschisis, laminar cortical necrosis and encefalomalacia with exvacuum dilation [4-9].

During the subacute-chronic phase of cerebral infarction, many physicians can inform the images as negative and may even not associate these imaging findings with primary ischemic damage, interpreting them as independent events, thus modifying the diagnosis

The object of this work was to describe the occurrence of these imaging findings in a series of six patients with cerebral infarction during the subacute-chronic phase. The description of the subjects is represented in Table 1.

\section{Case Presentation}

\section{Case 1}

Three-year-old female patient with left hemiparesis and previous diagnosis of brain tumor. After a simple (Figure 1A) and contrasted (Figure 1B) CT scan performed between day 3-7 an increased density in the territory irrigated by the MCA and gyriform enhancement

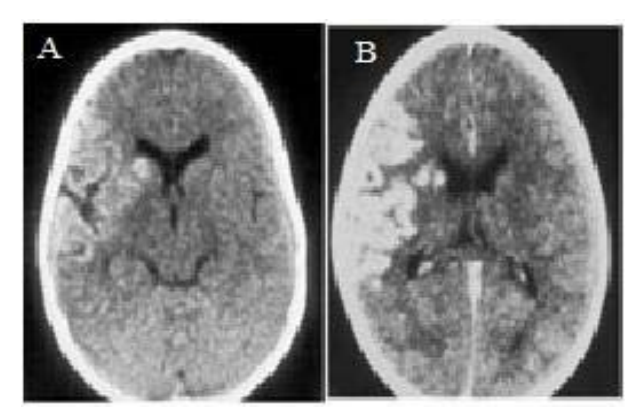

Figure 1: CT scan of the case 1 (A-Simple CT), (B-contrasted CT) showing luxury perfusion $(A)$ and gyri enhancement. $(B)$ in MCA territory.

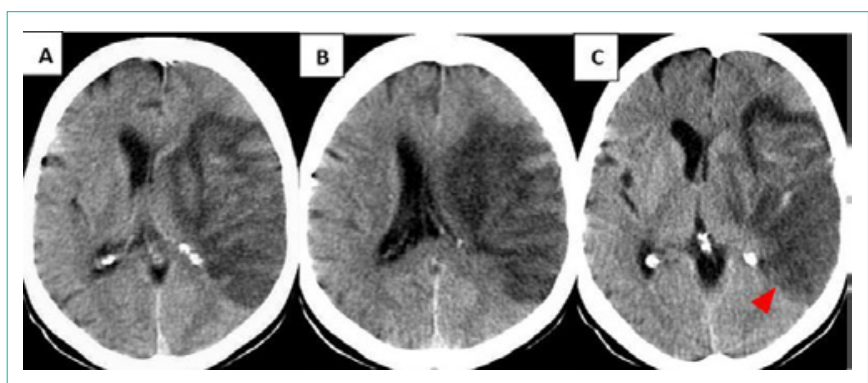

Figure 2: Luxury perfusion in CT scan at 8 days (A-B). At 13 days, the dense areas within the infarction start to disappear. (C) (red arrow head).

are found, due to luxury perfusion effect (Figure 1A,B). This effect confounds the real diagnostic of ischemic stroke and the images were interpreted as a brain tumor.

\section{Case 2}

Seventy-one-year-old female patient who presented sudden right hemiplejia and loss of consciousness. CT was performed 4 hours after the event and was considered normal. Due to unfavorable evolution, the study was repeated after 8 days (Figure 2A,B) and after 13 days (Figure $2 \mathrm{C}$ ). In A and B an infarct of the right MCA can be seen, with mass effect on the neighboring ventricle (which is collapsed) and slight displacement of the midline. Hyperdensity within the affected vascular territory follows the organization of gyri, contrasting with
Austin J Cerebrovasc Dis \& Stroke - Volume 4 Issue 3 - 2017 ISSN : 2381-9103 | www.austinpublishing group.com Hernández-Díaz et al. (C) All rights are reserved
Citation: Hernández-Díaz ZM, Barroso-García E, González-García S, González-Quevedo A, Reyes-Berazaín A and Arteche-Prior M. Confounding Imaging Findings in Subacute-Chronic Cerebral Infarction. Austin J Cerebrovasc Dis \& Stroke. 2017; 4(3): 1063. 


\begin{tabular}{|c|c|c|c|c|}
\hline Case & $\begin{array}{l}\text { Agel } \\
\text { Sex }\end{array}$ & Type of study & Effecto observed/time from infarct onset & Simulation \\
\hline 1 & $3 F$ & $\begin{array}{l}\text { Simple and } \\
\text { contrasted CT }\end{array}$ & Luxury Perfusion/ 3 days & Tumor \\
\hline 2 & $71 \mathrm{~F}$ & Simple CT & Luxury Perfusion/ 8 and 13 days & Hemorrhagic transformation of the infarct \\
\hline 3 & $56 \mathrm{M}$ & \begin{tabular}{c|} 
Simple CT \\
2nd simple CT
\end{tabular} & Fogging effect/17 days & Interpreted as a normal study, no previous evaluation \\
\hline 4 & $60 \mathrm{M}$ & Simple CT & $\begin{array}{l}\text { Hemorrhagic transformation } / 3,10,20,25 \\
\text { days }\end{array}$ & Intraparenchymal hematoma at day 10 \\
\hline \multirow{6}{*}{5} & \multirow{6}{*}{$35 \mathrm{~F}$} & Simple CT & Fogging effect / 21 days & Informed as normal \\
\hline & & $\begin{array}{l}\text { 1sr MRI T2, } \\
\text { FLAIR }\end{array}$ & Fogging effect / 21 days & Possible Multiple Sclerosis \\
\hline & & Contrasted MRI & $\begin{array}{l}\text { Luxury Perfusion, gyriform enhancement/ } \\
28 \text { days }\end{array}$ & The study was described without offering diagnosis \\
\hline & & $\begin{array}{c}\text { Followup } \\
\text { Multislice CT }\end{array}$ & $\begin{array}{l}\text { Hypodensity with slight mass effect on the } \\
\text { ipsilateral ventricle and laminar cortical } \\
\text { necrosis / } 35 \text { days }\end{array}$ & Possible low grade glioma \\
\hline & & MRI T1, FLAIR & $\begin{array}{l}\text { Encephalomalacia with ventricular dilation } \\
\text { exvacuum and gliosis/ } 3 \text { months }\end{array}$ & $\begin{array}{l}\text { Chronic infarct was informed with ventricular asymmetry andgliosis was } \\
\text { interpreted as edema. Edema }\end{array}$ \\
\hline & & $\begin{array}{l}\text { Last MRI T2 y } \\
\text { FLAIR }\end{array}$ & $\begin{array}{l}\text { Wallerian Degeneration / } 1 \text { year and } 9 \\
\text { months }\end{array}$ & Chronic Infarct in the brain stem independent from the supratentorial infarct \\
\hline \multirow[t]{2}{*}{6} & \multirow[t]{2}{*}{$65 \mathrm{~F}$} & \multirow[t]{2}{*}{$\begin{array}{l}\text { MRI T2, FLAIR } \\
\text { y T1 }\end{array}$} & $\begin{array}{l}\text { Chronic Infarct of the right MCA } \\
\text { Encephalomalacia with exvacuum ventricular } \\
\text { dilation/ } 2 \text { years and } 4 \text { months } \\
\text { Wallerian Degeneration } 2 \text { years and } 4 \\
\text { months }\end{array}$ & \multirow[t]{2}{*}{$\begin{array}{l}\text { The three findings were interpreted as independent conditions (chronic infarct, } \\
\text { ventricular asymmetry, atrophia of the right cerebral peduncle and of the left } \\
\text { hemicerebellum) }\end{array}$} \\
\hline & & & Diaschisis/ 2 years and 4 months & \\
\hline
\end{tabular}

the hypodensity resulting from necrosis and inflammation of the subacute infarct (luxury perfusion). In Figure 2C, it can be observed those 5 days later, the mass effect persists and the dense areas within the infarction start to disappear (red arrow head).

Luxury perfusion is defined as the cerebral blood flow (CBF) reaching the brain post stroke, which is above those levels necessary to fulfill the metabolic needs of the tissue [4]. When an artery is occluded and recanalization does not occur spontaneously or through a therapeutic procedure in a time period during which brain tissue is still viable, permanent neuronal and glial damage occurs, irremediably leading to parenchymal necrosis (cerebral infarction) [10].

"Luxury perfusion" starts about the $5^{\text {th }}$ day post stroke and lasts for several weeks. During this phase CBF increases progressively and frequently reaches values above normal levels at approximately 8 to 12 days, indicating that reperfusion is no longer useful in a tissue irreversibly damaged and probably reflecting futile recanalization [11] or neovascularization with abnormal autoregulation [10]. As demonstrated by SPECT $[4,12]$, oxygen and glucose consumption in this zone is highly reduced or even null. Other mechanisms involved in this phenomenon are ruptured blood brain barrier [4,7], which together with dilated capillary and venous proliferation, lead to increased density of the infarcted area. Luxury perfusion is revealed more clearly with the administration of contrast due to giriform enhancement $[13,14]$.

It can be mistaken with other conditions, mainly with hemorrhagic transformation of the infarct. It can also be mistaken with CNS primary tumors due to the mass effect it can produce on the ventricular system, as during this period vasogenic edema is evident. Diagnostic doubts can be discarded evaluating the initial images, where indirect and early signs of infarction should be looked for. It

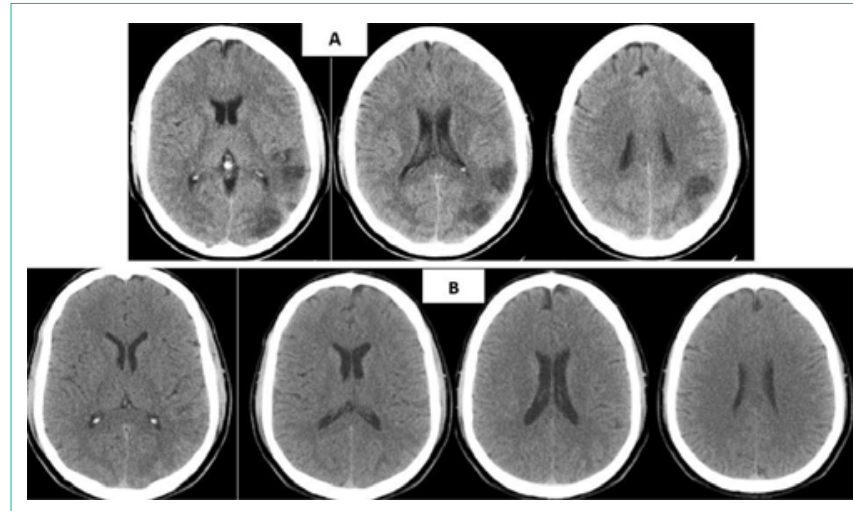

Figure 3: CT scan at 24 hours showing cerebral infarction (A). CT scan repeated 17 days later the infarct is totally masked due to the fogging effect (B).

should be taken into account that CT scanning can be normal when performed during the first hours after symptom onset. Nevertheless, combining neuroimaging studies is always a good option in order to establish differential diagnosis. Luxury perfusion in subacute infarction exhibits giriform enhancement, which most tumors do not show.

\section{Case 3}

A CT scan was performed 24 hours after ischemic stroke in a 56-year-old male patient with hypertension and hypercholesterolemia showing a hipodensity in the superficial territory of the left MCA (Figure 3A). CT scan repeated 17 days later and the infarct is totally masked due to the fogging effect, and interpreted as a normal study (Figure 3B), because no previous evaluation was considered.

Fogging effect was described for the first time in 1979 by Becker, et al. [15], involving in brain infarct the transition from hypodensity 


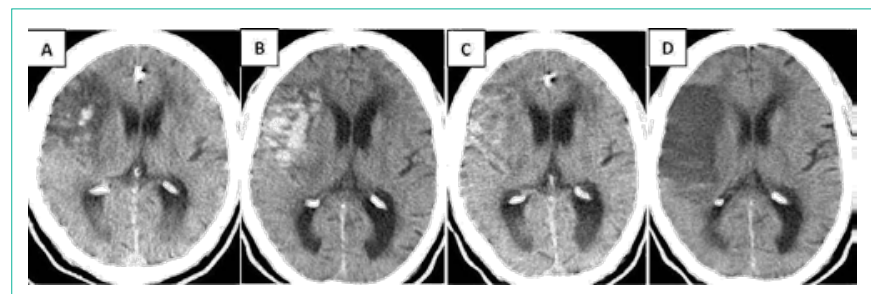

Figure 4: Serial CT scan at 3 (A), 10 (B), 20 (C), 25 (D) days showing hemorrhagic transformation of the infarction until the returning of the hypodensity (D). In C a fogging effect is observed.

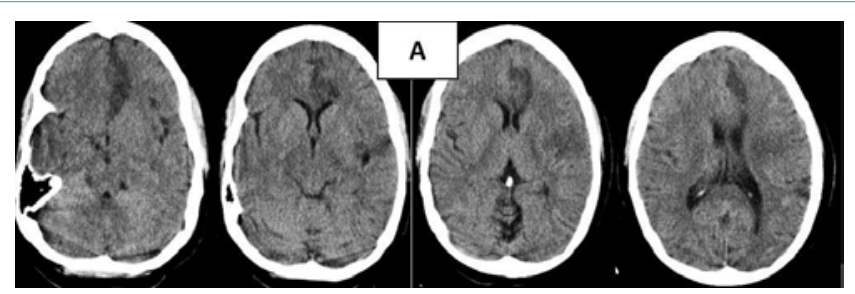

Figure 5A: CT scan demonstrated an acute infarct of the left MCA and ACA at 36 hours.

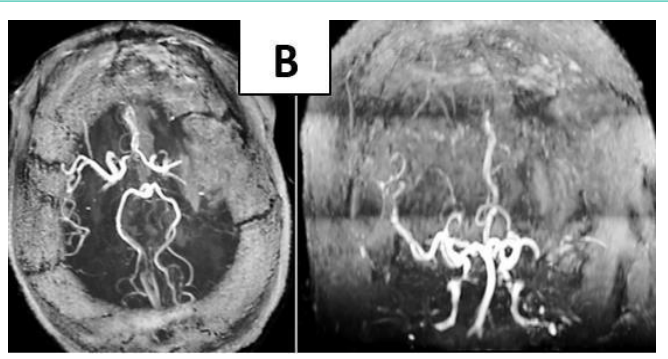

Figure 5B: Occlusion of the MCA and late recanalization of the left ACA is visualized in the angioresonance.

to a zone with normal attenuation. It occurs through the combination of several processes including the invasion by macrophages loaded with lipids [16], capillary proliferation, leukocyte infiltration and extravasation of blood cells through the walls of the lesioned blood vessels [5].

This effect is related with luxury perfusion, with increased blood flow concealing the radiological hypodensity in CT scans [3] associated with decreased brain edema $[14,15]$. Transient changes in the affected zones have also been described in MRI, where it can appear even from the sixth day after acute stroke [11].

It appears in up to $50 \%$ of subacute infarcts, more frequently between the 2nd and 3rd weeks after the event, and it does not last more than 6 months [16-17]. This phenomenon could be mistaken with a normal study, because when fogging effect appears false negatives increase during follow up and the size of infarcts can be underestimated.

\section{Case 4}

A male of 60 years-old, which CT scan, shows an infarct in the territory of the right MCA, which evolution demonstrate a hemorrhagic transformation, but at day 10 it was confused with and intraparenchymal hematoma. The first scan (Figure 4A) shows an infarct with petechial hemorrhage, while in Figure $4 \mathrm{~B}$ there is increased bleeding with petechial confluence producing a slight mass effect on the adjoining ventricle. After 17 days (Figure 4C) the blood is almost isodense with respect to the neighboring brain parenchyma, demonstrating that fogging effect in the course of subacute hemorrhagic transformation of infarcts, due to the degradation of hemoglobin, causes a transition of the infarct from hypodensity to isodensity. In Figure 4D the hypodensity of the infarct returns.

The hemorrhagic transformation is a complication, which appears in $90 \%$ of cardioembolic infarcts and in $65 \%$ of arterial infarcts spontaneously, or post fibrinolysis [18]. It occurs as a consequence of blood extravasation to the infarcted tissue due to early damage of the blood brain barrier and the secondary inflammatory effect in response to the arrival of plasmatic components to the brain tissue. This blood reaches the damaged vessels through recanalization of the occluded artery or through collaterals $[19,20]$. Diagnostic errors could be with hypertensive intraparenchymal hematoma, amyloid angiopathy, bleeding tumor, luxury perfusion and cortical laminar necrosis.

\section{Case 5}

A CT scan in a 35-year-old female patient, receiving oral anticonception drugs, demonstrated an acute infarct of the left MCA and anterior cerebral artery (ACA) (Figure 5A). Occlusion of the MCA with scarce collateral circulation and late recanalization of the left ACA is visualized in the angioresonance (Figure 5B).

21 days later, due to the fogging effect the image was interpreted as normal (Figure 5C), where CT scan only shows partial blurring of the left Sylvian valley. In MRI study, the sequences FLAIR (Figure 5D) and T2 (Figure 5E) shown crown radiated hyperintensities near the left lateral ventricle (red arrow head), these images were evaluated as possible multiple sclerosis.

At 28 days, a contrast T1-MRI was performed showing a gyriform enhancement due to a damaged blood brain barrier and luxury

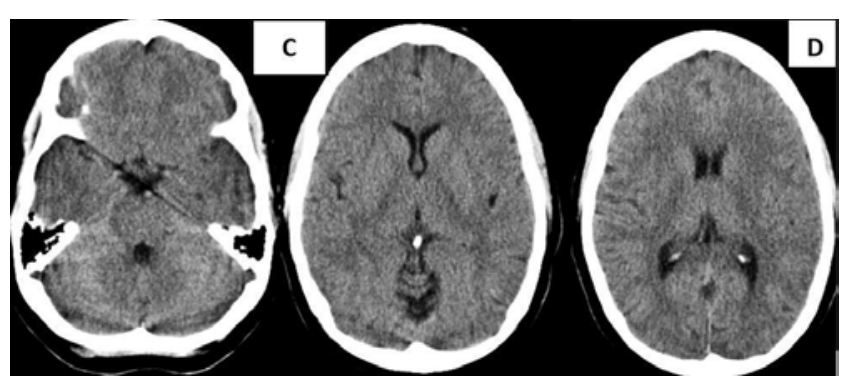

Figure 5C-D: The fogging effect in CT scan at 21 days. The image was interpreted as normal, and in D CT scan only shows partial blurring of the left Sylvian valley.

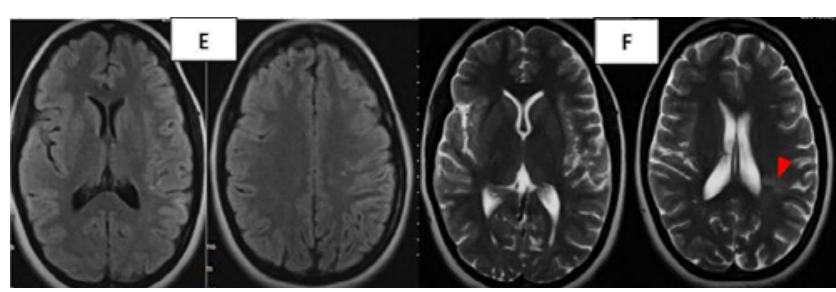

Figure 5E-F: MRI study visualizing crown radiated hyperintensities near the left lateral ventricle (red arrow head) due to the fogging effect. 


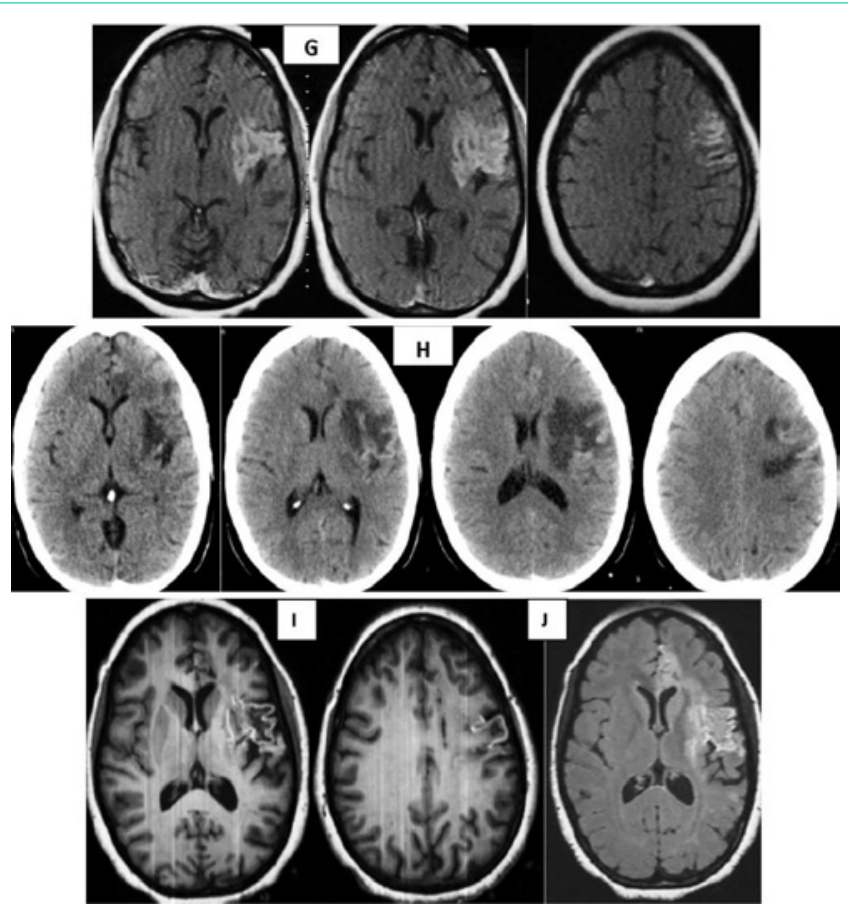

Figure 5G-J: MRI performed 40 days after the previous CT scan show laminar cortical necrosis in the superficial territory of left MCA and ACA with associated gliosis. Area of encephalomalacia in axial T2 sequence is shown (J)

perfusion (Figure 5F).

In an evolutive evaluation, a simple CT scan performed 35 days after symptom onset shows an hypodense lesion with a slight mass effect on the ipsilateral ventricle and hyperdense curved lines following some gyri (laminar cortical necrosis); which was mistakenly interpreted as a possible tumor (Figure 5G). Sequences T1 and FLAIR in an MRI performed 40 days after the previous CT scan show laminar cortical necrosis in the superficial territory of left MCA and ACA with associated gliosis (Figure 5H,I).

Laminar cortical necrosis is due to unequal destruction of the neocortex with preservation of some layers and impairment of others (layers 3-5), accompanied by gliosis [21], and appearing during the late subacute and chronic stages of cerebral infarct. It occurs when the influx of oxygen and glucose are inadequate for maintaining regional cerebral metabolism as in cerebral infarct, hypoxia, cerebral hipoperfusion and hipoglicemia or due to an increased demand (status epilepticus) [22]. They are visualized in MRI as cortical curvelined hyperintensities that follow the gyri pattern in $\mathrm{T} 1$ sequences without contrast and FLAIR. This hypersignal in T1 is caused by the accumulation of macromolecules, lipid-laden macrophages and no for the presence of blood or calcium [21]. It can be mistaken with the presence of blood in the infarct. Cortical necrosis is evident two weeks after infarction, with a peak of highest intensity at about one month, slowly disappearing after 3 or more months [23]. Occasionally it can be seen a year after infarction.

Evolution of the infarct to chronicity 3 months after the ischemic event. Area of encephalomalacia in axial (Figure 5J) and sagital T2 (Figure $5 \mathrm{~K}$ ) sequences. Impairment of the left half of the genu and

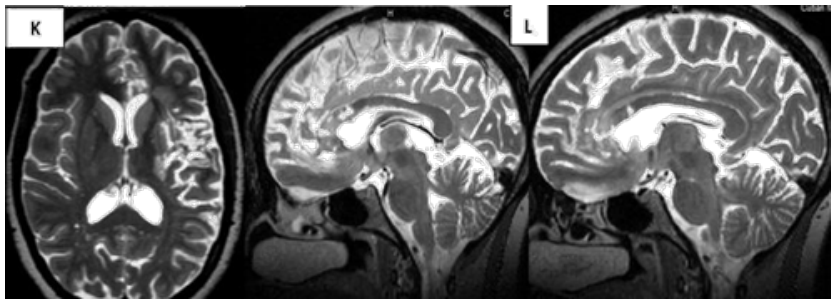

Figure 5K-L Areas of encephalomalacia in axial (K) and sagital T2 (L) MRI sequences 3 months after the ischemic event.

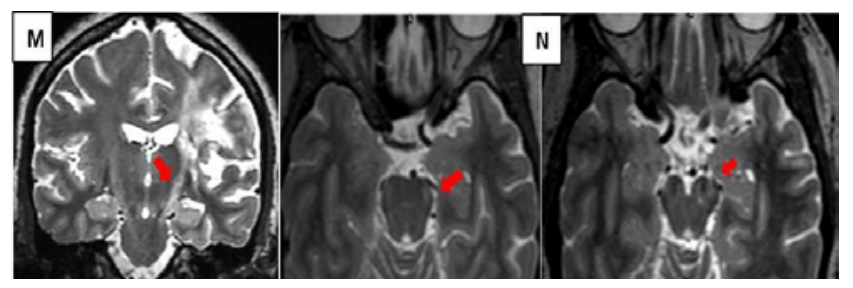

Figure 5M-N: In T2 axial a small hyperintensity in the left border of the pons and cerebral peduncle ipsilateral to ischemic damage due to Wallerian degeneration (red arrows).

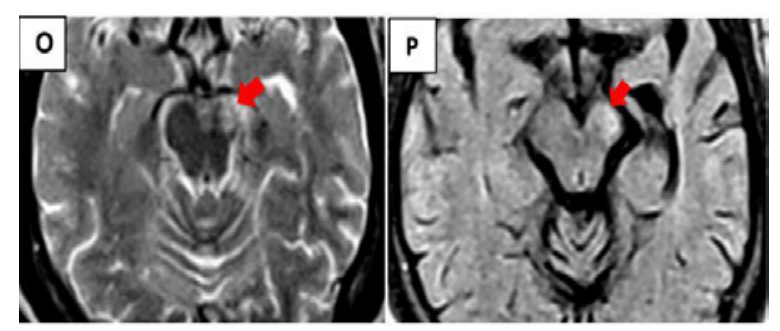

Figure 50-P: Two years later the sequences axial T2 and FLAIR show hyperintensity due to gliosis and atrophy in the left cerebral peduncle (red arrows), greater dilation of the temporal horn as well as hippocampal atrophy on that side.

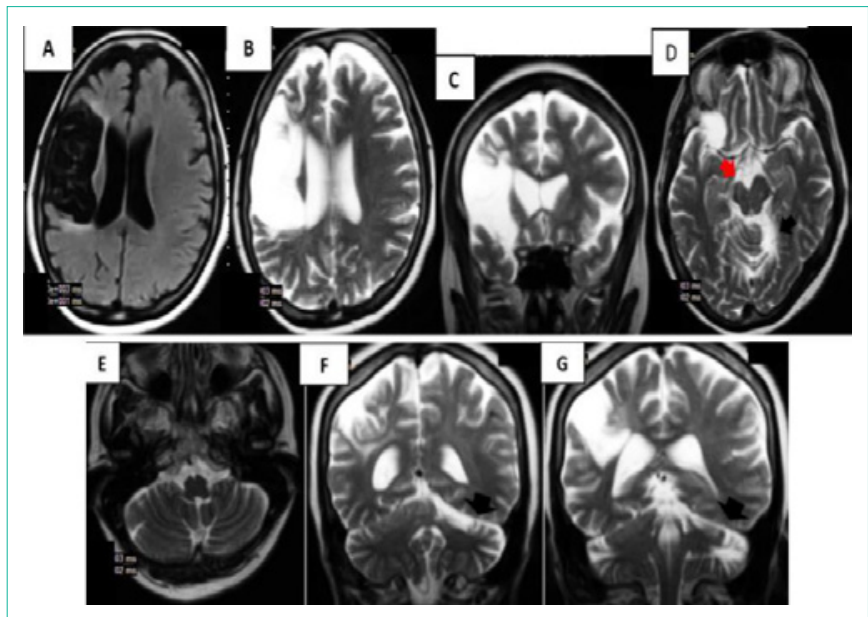

Figure 6 A-G: Cerebral infarction, hypointense in FLAIR (A) and hyperintense in T2 (B-C). Wallerian degeneration causes assymetry of the right cerebral peduncle (red arrow in $\mathrm{D}$ ). Atrophy of the contralateral cerebellar hemisphere (left) secondary to diaschisis is shown with black arrows (D-G).

anterior part of the corpus callosum's truncus, typical of cerebral infarcts is evident, because tumors cross the midline. The anterior 
cingulum is also affected, concurring with cognitive decline in this patient.

Figure 5L shows fronto temporo insular atrophy with increased frontal subarachnoid space and of the left Sylvian valley in a coronal T2 slice; hyperintensity of the left cortico-spinal tract starting in the area of residual encephalomalacia from chronic infarction (red arrow). In $\mathrm{T} 2$ axial (Figure $5 \mathrm{M}$ ) a small hyperintensity in the left border of the pons and cerebral peduncle ipsilateral to ischemic damage due to Wallerian degeneration (red arrows).

Encephalomalacia is the residual cavity remaining as a sequel after brain damage, with neuronal and glial death that interrupts the architecture of normal brain parenchyma, secondary to any acute event: ischemic (chronic infarct), hemorrhagic, traumatic, surgical, etc $[24,25]$. This leads to loss of local volume, gliosis and dilation of the ventricle ipsilateral to the lesion, thus being easily identified in neuroimaging studies $[24,25]$.

Figures 5N,O,P two years later (axial T2 and FLAIR sequences respectively) show hyperintensity due to gliosis and atrophy in the left cerebral peduncle (red arrows), greater dilation of the temporal horn as well as hippocampal atrophy on that side. The later images were interpreted as another brain stem infarct and not as Wallerian degeneration secondary to the chronic infarct in the territory of the left MCA two years ago, the same as hippocampal atrophy and dilation of the temporal horn.

Wallerian degeneration (WD) is a progressive demyelinating process of the distal ending of the axon after proximal damage that leads to axonal atrophy, gliosis and secondary loss of volumen. It is a distant sequel of the primary event [4]. The most affected pathway is the pyramidal tract, but damage in the optic pathway, corpus callosum and pontocerebellar fibers has also been described [26-28]. Although the most frequent cause is cerebrovascular disease, it can appear after any other event damaging the origin of the pathways as in infarcts, hemorrhages, encephalic trauma, surgery, frontotemporal dementias, multiple sclerosis and others [29].

Degeneration of the corticospinal tract is easily visualized in coronal T2 sequences, displaying hyperintensity throughout the length of the damaged tract from the chronic infarct in the territory of the medial cerebral artery to the ipsilateral cerebral peduncle. During the following years the cerebral peduncle and pons on the same side of the infarcted territory can appear hyperintense in T2 and FLAIR and atrophied; both could appear in CT scans and MRI [30]. In this case, atrophy and hyperintensity of the cerebral peduncle could be mistakenly reported as isolated events and not as a consequence of the primary event, in this case, chronic infarct.

\section{Case 6}

Is a sixty eight year old female patient with a story of arterial hypertension and a cerebral infarct two years and 4 months ago? In Figure 6 is observed encephalomalacia with exvacuum dilation of the ipsilateral ventricle secondary to a chronic infarct in the territory of the right MCA. The infarct appears hypointense with surrounding hyperintense gliosis in FLAIR (Figure 6A) and hyperintense in T2 (Figure 6B,C). Assymetry of the right cerebral peduncle is evident, which appears smaller (red arrow in Figure 6D) due to Wallerian degeneration. Black arrows denote atrophy of the contralateral cerebellar hemisphere (left) secondary to diaschisis (Figure 6D-G).

Diaschisis is a functional inhibition leading to loss of excitability because of a unilateral lesion in a distant zone, not having been lesioned directly, but still interconnected [31]. Crossed cerebellar diaschisis refers to a unilateral lesion (in this case a cerebral infarct) that can result in decreased $\mathrm{CBF}$ in the contralateral cerebellar hemisphere $[31,32]$ that can be reversible or not and can evolve in time towards atrophy due to deafferentation or selective neuronal death.

CT and MRI can show a chronic infarct of MCA territory and atrophy of the contralateral hemicerebellum [33]. Confounding diagnosis in this case is reporting cerebellar hemiatrophy as an event, which is independent from the primary ischemic damage.

\section{Conclusion}

It is very important to consider in the subacute phase of a cerebral infarct the imaging findings previously described, which appear frequently. Evaluating previous images, the use of contrast substances and combining images contributes to achieve more precise diagnoses. In the chronic phase of an infarct, local and distant sequels of the primary ischemic event should be sought.

\section{References}

1. Copen WA, Schaefer PW, Wu O. MR perfusion imaging in acute ischemic stroke. Neuroimaging Clin N Am. 2011; 21: 259-283.

2. Sánchez-Chávez JJ1. The penumbra area. Rev Neurol. 1999; 28: 810-816.

3. Yannes M, Frabizzio JV, Shah QA. Reversal of CT hypodensity after acute ischemic stroke. J Vasc Interv Neurol. 2013; 6: 10-14

4. Sánchez JJ, Barroso E, Cubero L, Gonzáles J, Farach M. Evaluación mediante TC, SPECT y qEEG de pacientes con lesiones isquémicas cerebrales durante las fases aguda, subaguda y crónica. Rev Neurol. 1998; 27: 213-23.

5. Ricarte IF, Pedroso JL, Carvalho FA, Abrahão A, Valiente RA, Alves MM, et al. The essential can be invisible to the eyes: the "fogging effect" phenomenon in the subacute stage of ischemic stroke. J Stroke Cerebrovasc Dis. 2013; 22 : e628-629.

6. Thomalla G, Glauche V, Weiller C, R"other J. Time course of wallerian degeneration after ischaemic stroke revealed by diffusion tensor imaging. $J$ Neurol Neurosurg Psychiatry. 2005; 76:159-160.

7. Bang OY, Saver JL, Alger JR, Shah SH, Buck BH, Starkman S, et al. Patterns and predictors of blood-brain barrier permeability derangements in acute ischemic stroke. Stroke. 2009; 40: 454-461.

8. Gorostiza D, Mateos B, Berástegui M, Escudero I, Iturre B. Afectación difusa del cerebelo en la edad pediátrica: hallazgos en resonancia magnética. Radiología. 2013; 55: 253-260.

9. Bermejo R, Cabada T, Bacaicoa MC, Ciriza M, Solchaga S. Degeneración walleriana bilateral de las fibras pontocerebelosas secundaria a ictus pontinos: presentación de 4 casos. Radiología. 2010; 52: 71-75.

10. Hernández-Díaz ZM, Reyes-Berazaín A, Buergo-Zuaznabar MA, ArtechePriorM. Neuroimaginología: bases bioquímicas y su aplicación en la enfermedad cerebrovascular isquémica. Medisur. 2009; 7.

11. Iglesias-Mohedano AM, García-Pastor A, Contreras-Chicote A, VillanuevaOsorio JA. ¿Está relacionado el fogging effect con la recanalización fútil? Neurología. 2015; 30: 447-449.

12. Cho IH, Hayashida K, Kume N, Shimotsu Y, Miyashita K. Visualization of pressure-dependent luxury perfusion in patient with subacute cerebral infarction. Ann Nucl Med. 1998; 12: 217-220.

13. Wing SD, Norman D, Pollock JA, Newton TH. Contrast enhancement of 
cerebral infarcts in computed tomography. Radiology. 1976; 121: 89-92.

14. Fabritius MP, Kazmierczak PM2, Thierfelder KM2, Kunz WG2. Reversal of CT Hypodensity in Chronic Ischemic Stroke : A Different Kind of Fogging Clin Neuroradiol. 2017.

15. Becker $H$, Desch $H$, Hacker $H$, Pencz A. CT fogging effect with ischemic cerebral infarcts. Neuroradiology. 1979; 18: 185-192.

16. Chalela JA, Kasner SE. The fogging effect. Neurology. 2000; 55: 315.

17. Shim YS, Yang DW. Clearing away the fogging effect at a Picture Archiving and Communication System (PACS). Clin Neurol Neurosurg. 2006; 108: 215216.

18. Nates M, Cisneros S, Gómez JJ, Grau M, Diez F, Grande D. Infartos hemorrágicos: causas, grados y posibles errores [Internet]. Granada: Sociedad Española Radiología Médica; 2012; 31.

19. Bang OY, Saver JL, Alger JR, Shah SH, Buck BH, Starkman S, et al. Patterns and predictors of blood-brain barrier permeability derangements in acute ischemic stroke. Stroke. 2009; 40: 454-461.

20. Dzialowski I, Pexman JH, Barber PA, Demchuk AM, Buchan AM, Hill MD; CASES Investigators. Asymptomatic hemorrhage after thrombolysis may not be benign: prognosis by hemorrhage type in the Canadian alteplase for stroke effectiveness study registry. Stroke. 2007; 38: 75-79.

21. Seong-Rok Han, Gi-Taek Yee, Chan-Young Choi, Chae-Heuck Lee. Cortica Laminar Necrosis in an Infant with Severe Traumatic Brain Injury. J Korean Neurosurg Soc. 2011; 50: 472-474.

22. Niwa T, Aida N, Shishikura A. Fujita K. Inoue T. Susceptibility-Weighted Imaging Findings of Cortical Laminar Necrosis in Pediatric Patients. AJNR Am J Neuroradiol. 2008; 29: 1795-1798.

23. Siskas N, Lefkopoulos A, loannidis I, Charitandi A, Dimitriadis AS. Cortical laminar necrosis in brain infarcts: serial MRI. Neuroradiology. 2003; 45: 283288.

24. Dubey $\mathrm{P}$, Lioutas VA, Bhadelia R, Manor B, Novak $\mathrm{P}$, Selim M, et al.
Quantitative micro structural deficits in chronic phase of stroke with small volume infarcts: A diffusion tensor 3-D tractographic analysis. Magn Reson Imaging. 2016; 34: 662-667.

25. Phadke RV, Agarwal V, Naik S. Multicystic encephalomalacia secondary to head trauma. J Neurosci Rural Pract. 2017; 8: 158-159.

26. Uchino A, Sawada A, Takase Y, Nojiri J, Kudo S. Wallerian degeneration of the middle cerebellar peduncle after pontine infarction: MR imaging. Radiat Med. $2004 ; 22: 37-41$

27. Bermejo T, Cabada, M.C. Bacaicoa, M. Ciriza, Solchaga S. Degeneración walleriana bilateral de las fibras pontocerebelosas secundaria a ictus pontinos: presentación de 4 casos. Comunicación breve Radiología. 2010; 52: 71-75.

28. Musson R, Romanowski C. Restricted diffusion in Wallerian degeneration of the middle cerebellar peduncles following pontine infarction. Pol J Radiol. 2010; 75: 38-43.

29. Singh S, Dallenga T, Winkler A, Roemer S, Maruschak B, Siebert H, et al. Relationship of acute axonal damage, Wallerian degeneration, and clinical disability in multiple sclerosis. Journal of Neuroinflammation. 2017; 14: 57.

30. Thomalla G, Glauche V, Weiller C, R"other J. Time course of wallerian degeneration after ischaemic stroke revealed by diffusion tensor imaging. $J$ Neurol Neurosurg Psychiatry. 2005; 76: 266-268.

31. Gorostiza Laborda D, Mateos Goñi B, Berástegui Imaz M, Escudero Martínez I, Iturre Salinas B. Diffuse brain involvement in paediatrics: magnetic resonance findings. Radiologia. 2013; 55: 253-260.

32. Abe K, Ukita H, Yorifuji S, Yanagihara T. Crossed cerebellar diaschisis in chronic Broca's aphasia. Neuroradiology. 1997; 39: 624-626.

33. Tien RD, Ashdown BC. Crossed cerebellar diaschisis and crossed cerebellar atrophy: correlation of MR findings, clinical symptoms, and supratentorial diseases in 26 patients. AJR Am J Roentgenol. 1992; 158: 1155-1159.
Austin J Cerebrovasc Dis \& Stroke - Volume 4 Issue 3 - 2017 ISSN : 2381-9103 | www.austinpublishing group.com Hernández-Díaz et al. (c) All rights are reserved
Citation: Hernández-Díaz ZM, Barroso-García E, González-García S, González-Quevedo A, Reyes-Berazaín A and Arteche-Prior M. Confounding Imaging Findings in Subacute-Chronic Cerebral Infarction. Austin J Cerebrovasc Dis \& Stroke. 2017; 4(3): 1063. 